\title{
Hubungan Gaya Belajar dengan Nilai Hasil Ujian Modul Sistem Gastro- intestinal, Hepatobilier Dan Pankreas Pada Mahasiswa Angkatan 2016 Fakultas Kedokteran Universitas Sam Ratulangi
}

\author{
${ }^{1}$ Novita A. Abay \\ ${ }^{2}$ Herlina I. S. Wungouw \\ ${ }^{2}$ Siemona Berhimpon
}

\author{
${ }^{1}$ Program Studi Pendidikan Dokter Fakultas Kedokteran Universitas Sam Ratulangi Manado \\ ${ }^{2}$ Medical Education Unit Fakultas Kedokteran Universitas Sam Ratulangi Manado \\ Email: novitaabay793@yahoo.com
}

\begin{abstract}
In an educational institution, achievement or performance of study is an important indicator to measure the success of teaching-learning process. Learning factors that can influence students' grades are internal and external factors. This study was aimed to obtain the relationship between learning style and students' grades in the gastrointestinal system, hepatobiliary, and pancreas module. This was an analytical study with a cross sectional design. Respondents were 90 students of batch 2016. Data were obtained by filling the learning style questionnaire and students' grades were obtained from the Academic Department. Data were analyzed by using the chi-square test. The chi-square test on dominant learning style showed a $P$ value of 0.989 meaning there was no significant relationship between dominant learning style and the grades, meanwhile on combined learning style the $P$ value was 0.410 which also meant that there was no relationship between learning style and the grades. Conclusion: There was no relationship between learning style and students' grades in the gastrointestinal system, hepatobiliary, and pancreas module among students of Faculty of Medicine, Sam Ratulangi University.
\end{abstract}

Keywords: learning style, students' grades

\begin{abstract}
Abstrak: Dalam suatu lembaga pendidikan, prestasi belajar merupakan indikator penting untuk mengukur keberhasilan proses belajar mengajar. Faktor belajar yang dapat memengaruhi hasil belajar mahasiswa ialah faktor internal dan faktor eksternal. Penelitian ini bertujuan untuk untuk mengetahui hubungan gaya belajar dengan nilai hasil ujian modul sistem gastrointestinal, hepatobilier dan pankreas. Jenis penelitian ialah analitik dengan desain potong lintang. dengan jumlah sampel sebanyak 90 orang mahasiswa angkatan 2016. Data didapatkan melalui pengisian kuesioner gaya belajar dan data nilai didapatkan dari bagian akademik. Uji analisis pada penelitian ini menggunakan uji chi-square. Hasil penelitian dengan uji chisquare pada gaya belajar dominan didapatkan nilai $P=0,989$ yang menunjukkan tidak terdapat hubungan bermakna antara gaya belajar dominan dengan hasil ujian, sedangkan untuk gaya belajar gabungan didapatkan nilai $P=0,410$ artinya tidak terdapat hubungan gaya belajar dengan hasil ujian. Simpulan: Tidak terdapat hubungan antara gaya belajar dengan nilai hasil modul gastrointestinal, hepatobilier, dan pankreas pada mahasiswa angkatan 2016 Fakultas Kedokteran Universitas Sam Ratulangi.
\end{abstract}

Kata kunci: gaya belajar, hasil belajar

Belajar merupakan suatu aktivitas yang bertujuan agar dapat memperlihatkan perubahan perilaku sebagai hasil dari pengalam- an yang sudah didapat. Belajar dapat dilakukan dengan mengamati, membaca, berinisiasi, mencoba sesuatu sendiri, 
mendengarkan dan mengikuti petunjuk/ arahan. $^{1}$ Hamalik $^{2}$ menjelaskan dalam bukunya bahwa tujuan dari pembelajaran ialah perubahan tingkah laku yang diharapkan tercapai oleh seseorang setelah melakukan suatu proses pembelajaran. ${ }^{2}$ Hasil proses pembelajaran akan tergambar pada prestasi belajar. Dalam suatu lembaga pendidikan, prestasi belajar merupakan indikator penting untuk megukur keberhasilan proses belajar mengajar. Faktor yang dapat memengaruhi perbedaan hasil belajar setiap mahasiswa ialah faktor internal dan faktor eksternal. Faktor internal adalah faktor yang berasal dari diri individu yang sedang belajar sedangkan faktor ekternal adalah faktor yang berasal dari luar individu. Salah satu faktor yang memengaruhi hasil belajar ialah gaya belajar. $^{3}$ Gaya belajar dapat menentukan prestasi belajar seseorang. Jika diberikan strategi yang sesuai dengan gaya belajarnya, seseorang dapat berkembang dengan lebih baik, gaya belajar otomatis tergantung dari masing-masing individu dimana individu mempunyai gaya belajar yang berbeda-beda. ${ }^{4}$ Honey dan Mumford membagi gaya belajar atas empat tipe, yaitu: gaya belajar reflektor, teoris, pragmatis. ${ }^{6}$

Menurut Slameto dan Suryabrata secara garis besar faktor-faktor yang dapat memengaruhi prestasi belajar dapat dikelompokkan atas faktor internal dan faktor eksternal. Yang termasuk faktor internal ialah kondisi fisiologi secara umum, kondisi psikologis, kondisi panca indera, intelegensi, bakat, dan motivasi sedangkan yang termasuk faktor eksternal ialah lingkungan alami dan sosial serta instrumental. ${ }^{7}$

\section{METODE PENELITIAN}

Jenis penelitian ini ialah analitik dengan desain potong lintang. Responden penelitian ialah mahasiswa semester 1 Program Studi Pendidikan Dokter di Fakultas Kedokteran Universitas Sam Ratulangi (Unsrat). Pengambilan data menggunakan kuesioner Honey dan Mumford. Untuk menentukan tipe gaya belajar dalam penelitian ini, kuesioner yang telah diisi oleh responden diberikan point pada setiap pilihan jawaban responden kemudian dihitung jumlah total keseluruhan pilihan masing-masing. Pilihan terbanyak atau point terbanyak merupakan tipe gaya belajar dari responden. Bila kedua hasil jawaban responden memiliki poin yang sama banyak maka kedua gaya belajar merupakan tipe gaya belajar responden.

Terdapat dua gaya belajar yaitu gaya belajar dominan dan gaya belajar gabungan. Gaya belajar dominan adalah gaya belajar yang merupakan poin tertinggi dari kuesioner (reflektor, pragmatis, teoris dan aktivis) sedangkan gaya belajar gabungan yakni antara dua gaya belajar yang didapat poin tertinggi dengan nilai yang sama pada dua gaya belajar yang berbeda (teoris/ pragmatis, reflektor/pragmatis, aktivis/ pragmatis, dan aktivis/reflektor. Nilai dalam penelitian ini ialah hasil ujian yang diperoleh dari ujian modul sistem gastrointestinal, hepatobilier dan pankreas sebelum diolah menjadi nilai akhir dan bukan nilai remedial. Nilai yang diambil yakni jumlah benar dimana 0-25 benar ialah sangat kurang, 25-50 benar ialah kurang, 51-75 benar ialah baik, dan 76-100 benar ialah sangat baik.

\section{HASIL PENELITIAN}

Gambar 1 menperlihatkan jumlah responden menurut jenis kelamin pada masing-masing gaya belajar. Pada gaya belajar dominan, dari 82 responden, sebagian besar ialah perempuan dengan jumlah 56 orang, sedangkan laki-laki berjumlah 26 orang. Pada gaya belajar gabungan dari 8 responden, sebagian besar ialah perempuan dengan jumlah 5 orang, sedangkan laki-laki berjumlah 3 orang.

Gambar 2 memperlihatkan gaya belajar dominan dari 82 responden. Sebagian besar responden mempunyai gaya belajar jenis reflektor dengan jumlah 59 orang dan paling sedikit ialah gaya belajar teoris dengan jumlah 5 orang.

Gambar 3 memperlihatkan gaya belajar gabungan dari 8 responden. Sebagian besar responden mempunyai gaya belajar gabungan jenis reflektor/pragmatis dengan jumlah 5 orang dan gaya belajar gabungan 
teoris/pragmatis, aktivis/pragmatis, dan aktivis/reflektor masing-masing 1 orang.

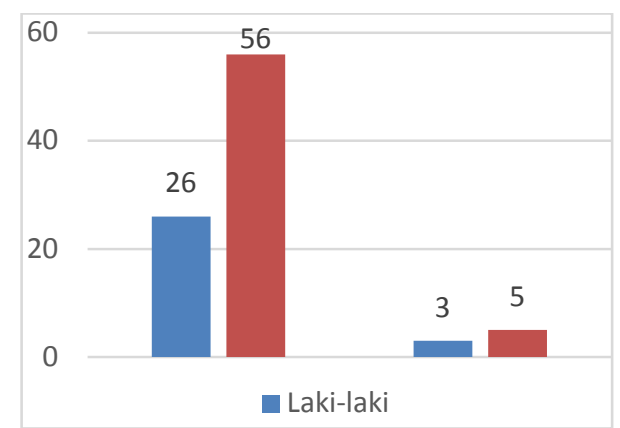

Gambar 1. Jenis kelamin menurut gaya belajar

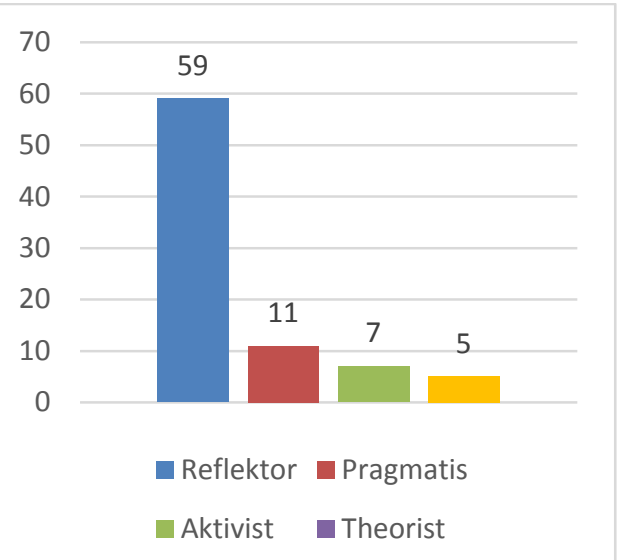

Gambar 2. Gaya belajar dominan

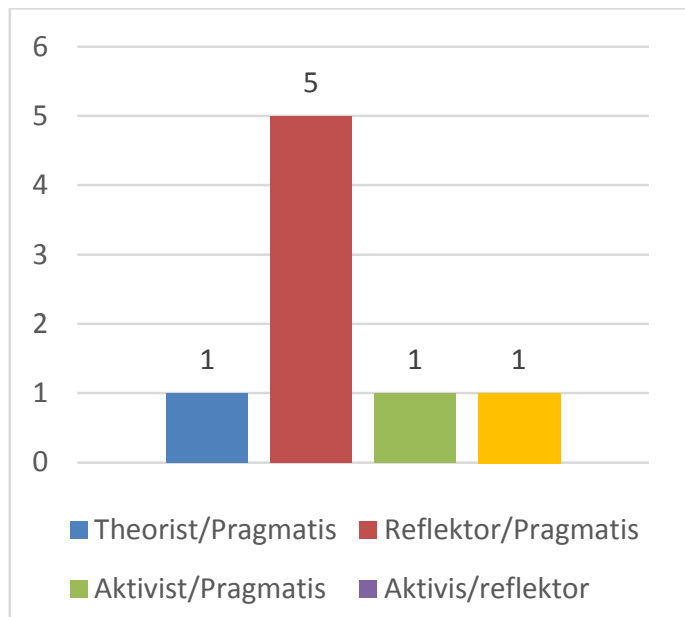

Gambar 3. Gaya belajar gabungan

Gambar 4 memperihatkan nilai modul pada masing-masing gaya belajar. Pada gaya belajar dominan dari 82 responden, sebagian besar responden mempunyai nilai modul kurang dengan jumlah 49 orang, nilai modul baik sebanyak 32 orang, dan nilai modul kurang sekali 1 orang. Pada gaya belajar gabungan dari 8 responden, sebagian besar responden mempunyai nilai modul baik berjumlah 5 orang, nilai modul kurang sebanyak 3 orang dan nilai modul kurang sekali tidak ada.

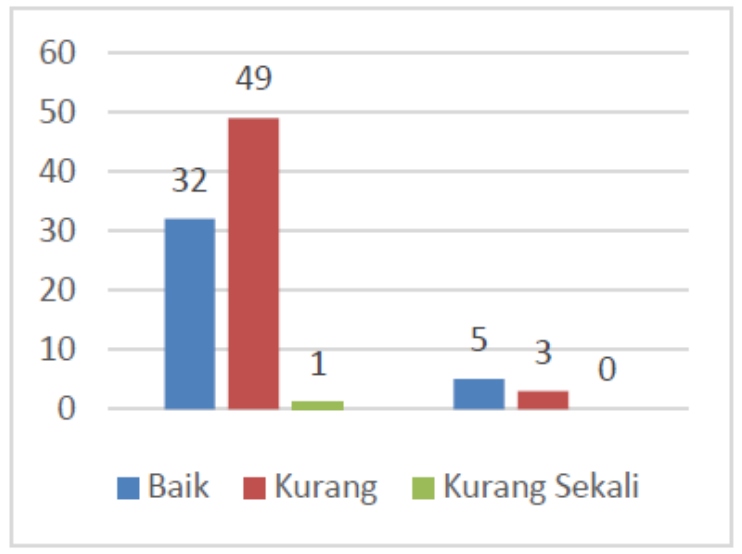

Gambar 4. Nilai modul menurut gaya belajar

Tabel 1 memperlihatkan bawa mahasiswa dengan gaya belajar dominan reflektor sebagian besar mempunyai nilai modul dengan kategori kurang berjumlah 35 orang, sedangkan yang kategori baik sebanyak 23 orang. Hasil analisis statistik menggunakan uji chi-square antara variabel gaya belajar dominan dengan nilai modul menggunakan $\alpha$ sebesar 5\% diperoleh nilai $P=0,989>0,05$, yang menunjukkan bahwa tidak terdapat hubungan bermakna antara gaya belajar dominan dengan nilai modul sistem gastrointestinal, hepatobilier dan pankreas pada mahasiswa Fakultas Kedokteran Unsrat.

Tabel 2 memperlihatkan bahwa mahasiswa dengan gaya belajar gabungan reflektor/pragmatis sebagian besar mempunyai nilai modul dengan kategori baik berjumlah 3 orang, sedangkan yang kurang sebanyak 2 orang mahasiswa. Hasil analisis statistik menggunakan uji chi-square antara variabel gaya belajar gabungan dengan nilai modul menggunakan $\alpha$ sebesar 5\% diperoleh nilai $P=0,410>0,05$ yang menunjukkan bahwa tidak terdapat hubungan bermakna antara gaya belajar gabungan dengan nilai modul sistem gastrointestinal, hepatobilier dan pankreas pada mahasiswa Fakultas Kedokteran Unsrat. 
Tabel 1. Hasil tabulasi silang gaya belajar dominan dengan nilai modul

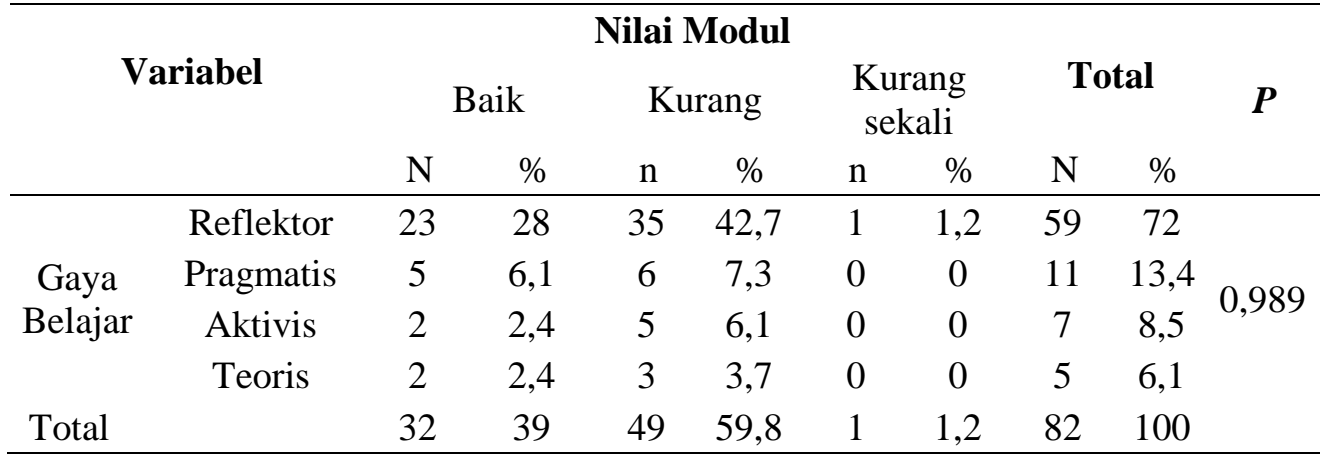

Tabel 2. Hasil tabulasi silang gaya belajar gabungan dengan nilai modul

\begin{tabular}{|c|c|c|c|c|c|c|c|c|c|c|}
\hline \multirow{3}{*}{ 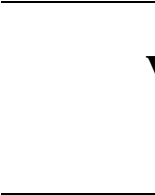 } & 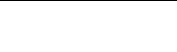 & \multicolumn{6}{|c|}{ Nilai Modul } & \multirow{2}{*}{\multicolumn{2}{|c|}{ Total }} & \multirow{3}{*}{$P$} \\
\hline & label & \multicolumn{2}{|c|}{ Baik } & \multicolumn{2}{|c|}{ Kurang } & \multicolumn{2}{|c|}{$\begin{array}{c}\text { Kurang } \\
\text { sekali }\end{array}$} & & & \\
\hline & & $\mathrm{n}$ & $\%$ & $\mathrm{~N}$ & $\%$ & $\mathrm{n}$ & $\%$ & $\mathrm{~N}$ & $\%$ & \\
\hline \multirow{4}{*}{$\begin{array}{l}\text { Gaya } \\
\text { Belajar }\end{array}$} & $\begin{array}{c}\text { Teoris/ } \\
\text { Pragmatis }\end{array}$ & 1 & 12,5 & 0 & 0 & 0 & 0 & 1 & 12,5 & \multirow{5}{*}{0,410} \\
\hline & $\begin{array}{l}\text { Reflektor/ } \\
\text { Pragmatis }\end{array}$ & 3 & 37,5 & 2 & 25 & 0 & 0 & 5 & 62,5 & \\
\hline & $\begin{array}{c}\text { Aktivis/ } \\
\text { Pragmatis }\end{array}$ & 1 & 12,5 & 0 & 0 & 0 & 0 & 1 & 12,5 & \\
\hline & $\begin{array}{l}\text { Aktivis/ } \\
\text { Reflektor }\end{array}$ & 0 & 0 & 1 & 12,5 & 0 & 0 & 1 & 12,5 & \\
\hline \multicolumn{2}{|l|}{ Total } & 5 & 62,5 & 3 & 37,5 & 0 & 0 & 8 & 100 & \\
\hline
\end{tabular}

\section{BAHASAN}

Hasil penelitian ini menunjukkan bahwa tidak terdapat hubungan bermakna baik antara gaya belajar dominan dengan nilai modul sistem gastrointestinal, hepatobilier dan pankreas maupun antara gaya belajar gabungan dengan nilai modul tersebut pada mahasiswa Fakultas Kedokteran Universitas Sam Ratulangi.

Hasil penelitian yang didapatkan sejalan dengan penelitian oleh Yokobus et al. yang menyatakan bahwa tidak terdapat hubungan antara gaya belajar dengan hasil belajar pada pembelajaran group investigation dengan nilai signifikansi $0,178>0,05$. $^{8}$ Penelitian serupa juga dilakukan oleh Ramlah et al. ${ }^{9}$ yang menyatakan bahwa tidak terdapat pengaruh interaksi metode pembelajaran kooperatif dan gaya belajar terhadap hasil belajar matematika dengan nilai signifikasi $0,180>0,05$.

Secara logika dapat dipahami bahwa tipe gaya belajar reflektor seharusnya mempunyai angka kecukupan yang baik sehingga akan memengaruhi nilai prestasi ataupun nilai modul yang diberikan tetapi hasil penelitian menunjukkan sebaliknya dimana ternyata sebagian besar mahasiswa masih mempunyai nilai modul dengan kategori kurang yakni $38,9 \%$. Hal ini mungkin didukung dengan pengalaman belajar mahasiswa yang belum terbiasa dengan Problem based learning (PBL) berbasis reflektor, teoris, aktivis, pragmatis dan gabungan gaya belajar lainnya mengingat responden masih duduk di bangku kuliah semester 1 atau baru menyesuaikan dengan proses pembelajaran ditingkat universitas. Walaupun demikian, terdapat mahasiswa yang sudah mempunyai nilai modul dengan kategori baik yakni $25,6 \%$. Hal ini didukung oleh pengalaman belajar sebelumnya di tingkat Sekolah Menengah Atas dan aktifitas positif mahasiswa seperti dalam 
penggunaan internet.

Pada tipe gaya belajar gabungan terdapat 8 orang yang mempunyai gaya belajar ini. Sebagian besar mahasiswa mempunyai gaya belajar gabungan ialah reflektor/pragmatis yang mempunyai nilai modul kategori baik yakni $37,5 \%$ dan kategori kurang 25\%. Tipe gaya belajar reflektor/pragmatis merupakan campuran gaya belajar reflektor dan gaya belajar pragmatis. Golongan reflektor adalah mereka yang dalam melakukan suatu tindakan sangat berhati-hati dan penuh pertimbangan. Pertimbangan-pertimbangan baik-buruk, untung-rugi, selalu diperhitungkan dengan cermat dalam memutuskan sesuatu. Individu demikian tidak mudah dipengaruhi, sehingga mereka cenderung bersifat konservatif. Golongan pragmatis adalah golongan yang memiliki sifat-sifat praktis, tidak suka berpanjang lebar dengan teoriteori, konsep-konsep, dan lainnya. Bagi mereka yang penting ialah aspek praktis, sesuatu yang nyata dan dapat dilaksanakan. Sesuatu hanya bermanfaat jika dapat dipraktekkan. Bagi kelompok ini sesuatu lebih baik dan berguna jika dipraktekkan, sehingga gabungan gaya belajar ini menghasilkan gaya belajar yang penuh pertimbangan dan praktis. Mahasiswa sudah mampu berpikir abstrak dan menggunakan alasan-alasan yang ilmiah, sehinga mereka memiliki kemampuan untuk memecahkan masalah yang kompleks termasuk mengembangkan alternatif pemecahan masalah yang dihadapi. Kemampuan mereka untuk melihat dari prespektif yang berbeda juga akan muncul, sehingga akan tampak bahwa mereka mampu melihat persoalan secara kritis, mereka tidak akan memroses informasi itu serta mengadaptasikannya dengan pemikiran mereka sendiri. ${ }^{10}$

\section{SIMPULAN}

Berdasarkan hasil penelitian ini dapat disimpulkan bahwa tidak terdapat hubungan gaya belajar dengan nilai hasil ujian modul gastrointestinal, hepatobilier dan pankreas pada mahasiswa angkatan 2016 Fakultas Kedokteran Universitas Sam Ratulangi.

\section{SARAN}

Disarankan agar institusi dapat memfasilitasi semua tipe gaya belajar mahasiswa dengan meningkatkan sarana prasarana pendidikan dan alat penunjang pembelajaran sehingga mahasiswa dapat memaksimalkan gaya belajar yang diminatinya

\section{DAFTAR PUSTAKA}

1. Sadirman. Interaksi dan Motivasi Belajar Mengajar. Jakarta: Raja Grafindo Persada, 2005.

2. Hamalik O. Proses Belajar Mengajar. Jakarta: PT Bumi Aksara, 2006.

3. Sugihartono. Psikologi Pendidikan. Yogyakarta: UNY Press, 2007.

4. Rahmati I. Pengaruh gaya belajar terhadap prestasi belajar bahasa arab kelas VII semester II di MTs N Ngalur [Skripsi]. Yogyakarta: Fakultas Tarbiyah dan Keguruan Universitas Islam Negeri Sunan Kalijaga; 2013.

5. Dermanta VD. Profil gaya belajar guru SMP dan SMA di Surabaya dikaji dari Faktor Sosiodemografis. Fakultas Psikologi Universitas Airlangga Surabaya. 2014. [cited 2018 Sept 17]. Available from: http://journal.unair. ac.id/download-fullpapersjppp372c15e0c0full.pdf

6. Padmasari Z, Wrastari AT. Hubungan antara gaya belajar dengan metode pengajaran guru SMA di Kawasan Surabaya. Jurnal Psikologis Klinis dan Kesehatan Mental. 2014;3(2):90-6.

7. Mustamin St H, Sulasteri S. Faktor-faktor yang mempengaruhi prestasi belajar mahasiswa Jurusan Pendidikan Matematika Fakultas Tarbiyah dan Keguruan UIN Alauddin Makassar. MaPan. 20131(1):151-77.

8. Mite Y, Corebima AD, Syamsuri I. Hubungan antara gaya belajar dengan hasil belajar siswa SMA Katolik Santa Maria Malang berbasis skor terkoreksi dalam pembelajaran biologi melalui pembelajaran group investigation (GI) tahun ajaran 2015/2016. Jurnal Pendidikan. 2016;1(5):822-7.

9. Ramlah, Firmansyah D, Zubair H. Pengaruh gaya belajar dan keaktifan siswa terhadap prestasi belajar matematika (Survey pada SMP Negeri di Kecamatan Klari Kabupaten Karawang). Jurnal 
140 Jurnal e-Biomedik (eBm), Volume 6, Nomor 2, Juli-Desember 2018

Unsika. 2014;3(1):68-75.

10. Hidayat DR. Permasalahan mahasiswa. pelatihan penasehat akademik Kopertis
Wilayah III Tahun 2011. Universitas Negeri Jakarta. [cited 2018 Sept 17]. Available from: www.kopertis3.or.id. 